\title{
Commentary
}

\section{Philosophy of Internal Medicine - Osler and Hinohara-ism}

\author{
Hiroshi Bando, MD, PhD, FACP* \\ Tokushima University/Medical Research, Nakashowa I-6I, Tokushima 770-0943, Japan

\section{*Corresponding author} \\ Hiroshi Bando, MD, PhD, FACP \\ Instructor, Tokushima University and Medical Research, Nakashowa I-6I, Tokushima 770-0943, Japan; Tel. +8I-90-3 I87-2485; Fax: +8I-88-603-I030; \\ E-mail:pianomed@bronze.ocn.ne.jp
}

\section{Article information}

Received: August $30^{\text {th }}, 2018$; Accepted: September $5^{\text {th }}, 2018$; Published: September $6^{\text {th }}, 2018$

Cite this article

Bando H. Philosophy of internal medicine - Osler and Hinohara-ism. Intern Med Open J. 20I8; 2(I): 7-9. doi: I0.I7I40/IMOJ-2-I07

C ongratulations for the upcoming issue of Internal Medicine Open Journal (IMOJ). I feel glad to observe the development of new world with many historical antecedent doctors. At first, I would like to introduce a prominent doctor, Shigeaki Hinohara, who has been well-known worldwide. ${ }^{1}$ He had been extremely active in various fields until 105 years as a physician in the St. Luke International Hospital, Tokyo, Japan. ${ }^{2}$

Formerly, he served as the president of the International Association of Internal Medicine, and contributed greatly to the development of medicine, medical practice, internal medicine, primary care, nursing, music therapy, and so on.

He passed away in July, 2017, and obituary articles were found in numerous medical journals. ${ }^{3,4}$ Among them, British Medical Journal (BMJ) introduces him as Oslerian scholar, prolific author, and peace advocate.

He was vibrant and hard working when he turned 100 in 2011 he was still practicing medicine, writing books, and giving inspirational talks and speeches. ${ }^{4}$ Perhaps Japan's most famous doctor, he was loved by millions and was considered a national treasure. ${ }^{2}$ On Culture Day (Nov 3, 2006), at the Imperial Palace in Tokyo, the Emperor awarded Dr. Shigeaki Hinohara the Order of Culture, the most prestigious governmental recognition in Japan . ${ }^{5}$

A devout Christian, Hinohara began his medical career in 1941 in Tokyo at St Luke's International Hospital, and was named chief of internal medicine in 1951 and hospital director in 1992. Hinohara fell under the spell of legendary physician and humanist William Osler in 1945 when he was given a gift of Osler's book Aequanimitas: With Other Addresses to Medical Students, Nurses, and Practitioners of Medicine. ${ }^{6}$ He was very impressed with the way of life of Sir Osler and became Oslerian scholar during his life. ${ }^{7}$ In 1983 he cofounded the Japan Osler Society and was an honorary member of the Osler Club of London and the American Osler Society. ${ }^{8,9}$

Historically speaking, 'internal medicine' has been born as the foundation of the general medicine. It has gradually developed and differentiated into several fields which are cardiovascular, respiratory, digestive, renal, endocrine/metabolism, infectious, immunology, neurology, hematology, and so on. These aspects are from the system of reviews or axis of organ. It is research-oriented categorization in pursuit of medical development and evolution.

The second aspect is medical practice of cure and care. It is always found in usual practice with physical, psychological and psychiatric treatment. In other words, this axis includes humanityoriented treatment along with the philosophy of Hinohara, which is called Hinohara-ism. ${ }^{1}$

The third one is medical education where senior doctor gives adequate advices to junior doctor. ${ }^{10}$ In educational hospitals such as university hospitals, three missions are research, clinical and education. Dr. Osler wrote down a textbook "The Principles and Practice of Medicine" and emphasized the importance of bed side teaching. Without bed side learning, a physician cannot raise various skills including diagnosis, therapy, medical technique, management, interpersonal communication skill, and so on.

There are 10 qualities taught and modeled by Sir William Osler as follows: 1 . Have ideas, preferably in writing, 2. Study time management, 3. Take care of yourself, 4 . Be a positive person, 5 . Take interest in your work, 6. Value education, 7. Read wisely and well, 8. Cultivate the humanities, 9. Appreciate your fellow humans, 
10. Accept the human condition.

As mentioned above, Dr. Hinohara and Dr. Osler left a big footprint in the history of internal medicine. ${ }^{11}$ These contents are common in the field of internal medicine and primary care medicine. When comparing the both, there are many similarities and differences. In the case of medical textbooks, the former is mainly described along to system of reviews. In the latter, the introduction and philosophy of medicine in the first chapter would be described wide and deeply.

From another aspect, internal medicine and primary care (PC) can be compared. There is a maxim by Sir Osler, "Medicine is an art based on science". ${ }^{12}$ In other words, medical science has objects targeted by science or by art. The former treats the body and deals with diseases. Science discovers and analyzes the law and leads it to diagnosis.

On the other hand, the latter analyzes not the body, but the heart, soul and heart of the sick person. In that case, we value emphasis on the characteristic personal information of the patients. From the standpoint of humanity, art emphasizes communication with subjects. Several examples of science $v$ s. art are observed as follows: disease $v s$. illness, case $v s$. patient, and evidence-based cure $v s$. warm-hearted care, effect of the therapy $v$ s. skilled art of manner.

It was Dr. Hinohara that introduced PC into Japan some decades ago. Consequently, he was called as 'The Father of PC in Japan', and respected by all of medical staffs and people. ${ }^{1} \mathrm{He}$ has emphasized the importance of psychosomatic care in PC and also 'the balance of mind and body".

As one of the disciples of Dr. Hinohara, I was trained in the family practice residency program in United States, and have endeavored to develop PC in Japan intra- and internationally. There was $8^{\text {th }}$ annual Congress of Japanese Primary Care Association (JPCA) in May 2017, in which I was the chairman of 5000 attendees and Dr. Hinohara gave us his last official message concerning the development of PC in Japan owing to his contribution. $^{13}$

Due to his advice, several medical associations in Japan have been established and developing so far. Among them, main medical related societies are JPCA, Japanese Society of Psychosomatic Internal Medicine (JSPIM), Japanese Society of Psychosomatic Medicine (JSPM) and so on. Concerning additional clinical role of internal medicine, some psychological and psychosomatic factors are expected to be involved in the future. ${ }^{14,15}$

Other contribution of Dr. Hinohara has been the foundation of the New Elderly Association (NEA) in 2000 and the launch the movement in Japan and other countries. ${ }^{1,16} \mathrm{NEA}$ adopted four slogans, which are to love, to initiate, to endure and to promote world peace. The important point was that good models of the aged would be shown to the young generation through hearty communication at their homes or at public places. ${ }^{17}$ Furthermore, Hinohara continued to persuade health professionals in different disciplines into working together more closely in order to improve the quality of health care. ${ }^{18}$

In summary, prominent physicians, Sir Osler and Dr. Hinohara are introduced in this article. Several topics related to Internal Medicine were also described in the axes of medical practice, research and education. Furthermore, the significance of science and art, and psychosomatic involvement was proposed. Scientific discoveries need to enhance, not replace, the art of medicine in the future practice.

\section{REFERENCES}

1. BandoH, Yoshioka A, Iwashimizu Y, Iwashita M, Doba N. Development of primary care, lifestyle disease and new elderly association (NEA) in Japan - common philosophy with Hinohara-ism. Prim Health Care. 2017; 7(3): 281. doi: 10.4172/2167-1079.1000281

2. Roberts S. Dr. Shigeaki Hinohara, Longevity Expert, Dies at (or Lives to) 105. New York, USA: New York Times. 2017; 127: 1.

3. Lock M. In memoriam: Dr. Shigeaki Hinohara 1911-2017. New York, USA: The Osler Library Newsletter. 2017.

4. Stafford N. Shigeaki Hinohara. BMJ. 2017; 358. doi: 10.1136/ bmj.j3891

5. Miller P. Dr. Shigeaki Hinohara receives the order of culture. New York, USA: The Osler Library Newsletter. 2006; 105: 7.

6. Hinohara S. Osler's peregrinations in Asia - A report on an unusual event. Am J Dis Child. 1972; 124(3): 344-346. doi: 10.1001/ archpedi.1972.02110150042006

7. Bryan CS. Osler's" A way of life" and other addresses, with commentary and annotations. Baltimore, Maryland, USA: John Hopkins University press. 2001; 76 (4) 834-836.

8. Hinohara S. Sir William Osler's philosophy on death. Annals of Internal Medicine. 1993; 118(8): 638. doi: 10.7326/0003-4819-1188-199304150-00012

9. Hinohara S. Facing death the Japanese way - customs and ethos. In: Hoshino K. Eds Japanese and Western Bioethics. New York, USA: Springer. 1997.

10. Tokuda Y, Hinohara S, Fukui T. Introducing a new medical school system into Japan. Ann Acad Med. 2008; 37: 800-802.

11. Osler W. On the educational value of the medical society. In: Aequanimitas with Other Addresses to Medical Students. Blakiston, Australia: Philadelphia. 1904. 
12. Seeman MV, Becker RE. Osler and the way we were taught. Med Sci Educ. 2017; 27: 555-557. doi: 10.1007/s40670-017-0419-Z

13. Japanese Primary Care Association (JPCA) 8th annual Congress in Shikoku Island. Website: http://www2.c-linkage.co.jp/ jpca2017/en/ . Accessed 2017.

14. Doba N, Tokuda Y, Saiki K, et al. Assessment of self-efficacy and its relationship with frailty in the elderly. Intern Med. 55: 27852792. doi: 10.2169/internalmedicine.55.6924

15. Tokuda Y, Okuba T, Ohde S, et al. Assessing items on the SF-8 Japanese version for health-related quality of life: a psychometric analysis based on the nominal categories model of item response theory. Value Health. 2009; 12(4): 568-573. doi: 10.1111/j.1524-

\subsubsection{9.x}

16. Hinohara S. Preparations to stay hale and hearty in your old age. J Jap Assoc Rural Med. 2007; 55(6): 553-564. doi: 10.2185/ jjrm.55.553

17. Ogaw T. Changing social concepts of age: Towards the active senior citizen. The Demographic Challenge: A Handbook about Japan. Leiden, Netherlands: Brill Publication. 2008.

18. Doba N, Hinohara $\mathrm{H}$, Yanai $\mathrm{H}$, et al. The new elder citizen movement in Japan. In: Matsumoto Y, Ed. Faces of Aging, the Lived Experience of the Elderly in Japan. Redwood City, California: USA: Stanford University Press. 2011. 